\title{
Effect of Increased Tensile Strength and Toughness on Reinforcing-Bar Bond Behavior
}

\author{
Neven Krstulovic-Opara
}

Department of Civil Engineering, Northeastern University, 417 Snell Engineering Center, Boston, Massachusetts 02115, USA

\section{Kimberly A. Watson}

Department of Aerospace Engineering, University of Michigan, Ann Arbor, Michigan 48109, USA

$\&$

\section{James M. LaFave}

Department of Civil and Environmental Engineering, University of Michigan, Ann Arbor, Michigan 48109-2125, USA

(Received 3 June 1993; accepted 15 November 1993)

\begin{abstract}
The research reported here investigated the pull-out behavior of deformed reinforcing bars embedded in fiber-reinforced-concrete (FRC) and high-performance-fiber-reinforced-concrete (HPFRC) matrices exhibiting increased tensile strength and toughness. Increased strength and toughness of the embedding matrix resulted in a significant increase in pull-out strength, strain capacity, and over-all ductility, as well as more stable crack development. Additionally, when sufficient lateral constraint (i.e. cover thickness) was provided, the use of an HPFRC matrix exhibiting strain-hardening behavior resulted in a slip-hardening pull-out response.
\end{abstract}

Key words: Bond (concrete to reinforcement); high performance fiber reinforced concretes; metal fibers; cracking; ductility, pullout tests; slippage.

\section{INTRODUCTION}

Reinforcing-bar pull-out is one of the main factors affecting the ultimate behavior and failure of structural elements. The pull-out behavior is a function of the bar characteristics (geometry and steel type), characteristics of the surrounding matrix, ${ }^{*}$ and the level of lateral confinement (e.g. cover thickness or the presence of stirrups).

\section{Bond behavior}

At the local level, the bond strength developed between two adjacent ribs of a deformed bar depends upon the concrete shear strength, $v_{\mathrm{c}}$, the concrete compressive strength, $f_{c}$, and the shear strength of the bond between concrete and bar, $v_{\mathrm{a}}$, as shown in Fig. 1(a). ${ }^{1}$ When the ratio between the rib spacing, $c$, and rib height, $a$, is less than about 10 , the concrete shear stress, $v_{c}$, will typically govern the pull-out behavior, and the bar will pull out, as shown in Fig. 1 (b). ${ }^{1}$ When the ratio is greater than 10 , which is the case with reinforcing bars used in this research, the pull-out behavior will be governed by the circumferential tensile stresses developed in the surrounding matrix, as shown in Fig. 1(c). ${ }^{1}$ Goto ${ }^{2}$ found that, once the concrete tensile strength is reached, so-called primary cracks develop along a plane perpendicular to the bar axis and propagate all the way to

*Matrix here refers to the composite surrounding a reinforcing bar, such as plain concrete, fiber-reinforced concrete (FRC), or high-performance FRC (HPFRC). 


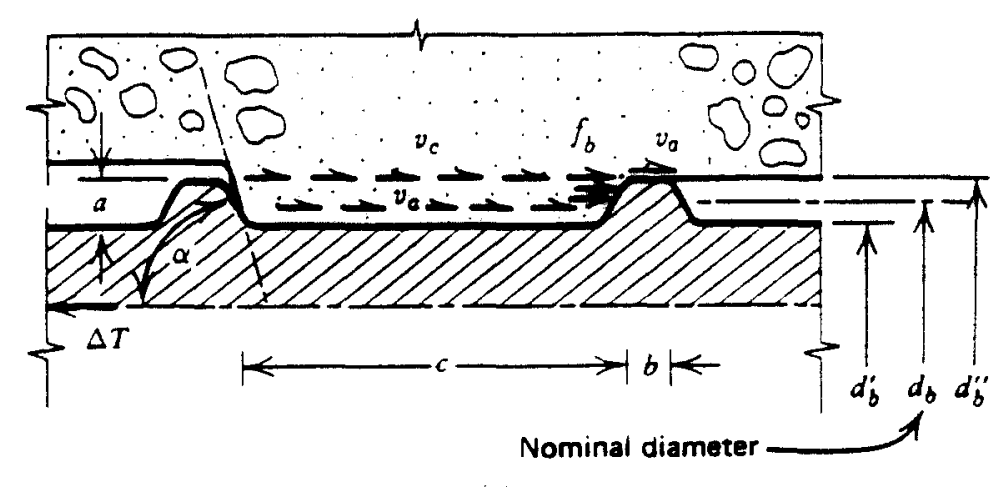

(a)

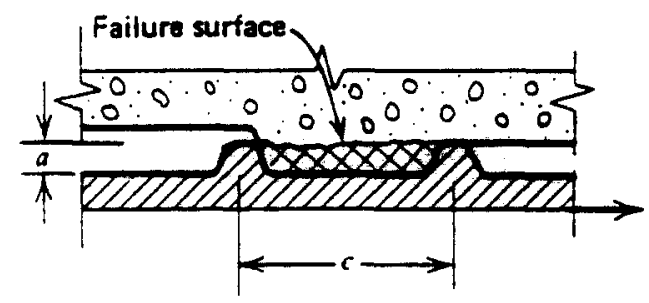

(b)

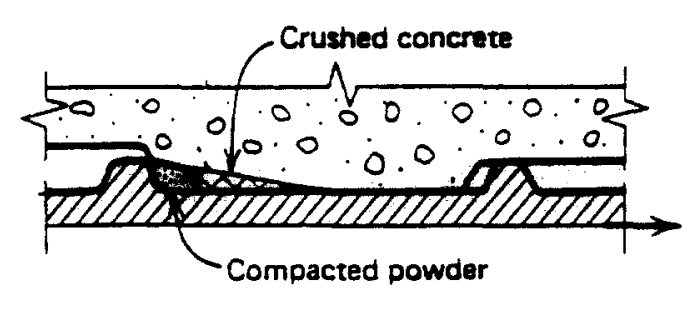

(c)

Fig. 1. Local behavior between two ribs of a deformed bar: (a) stresses developing between two adjacent ribs, (b) shear pullout failure mode at the ribs, and (c) failure by localized crushing followed by splitting of the matrix.'

the specimen's surface. As the load is further increased, the concrete starts pulling away from the bar in the vicinity of the primary cracks, and numerous internal secondary cracks develop at the ribs. Finally, high circumferential tensile stresses, developing in the vicinity of primary cracks, lead to the development of longitudinal cracks. ${ }^{2}$ These cracks result in premature splitting and bursting of the concrete cover, and, unless reinforcement is provided to restrain the opening of the longitudinal cracks, they will lead to a significant reduction in the bond strength. The load level at which a splitting failure occurs depends upon: (i) the minimum matrix cover thickness, (ii) the average bond stress (related to the embedment length and bar diameter), and (iii) the matrix tensile characteristics (e.g. tensile strength and strain capacity), such that the smaller the cover thickness and/or the higher the average bond stress, the lower is the splitting load. $\dagger$ However, whereas it is known that the splitting load increases with the improvement in the matrix tensile strength and tensile strain, the relationship between the improvement in the tensile characteristics and the resulting pull-out response is still not fully understood, as explained below.

† Since matrix tensile strength is constant for a given matrix, the ultimate load level depends upon the cover thickness and bar diameter (related to the average bond stress).

\section{Effect of matrix characteristics}

Various authors have investigated the pull-out behavior of bars embedded in concrete, ${ }^{\mid-11}$ polypropylene-fiber-reinforced concrete, ${ }^{9}$ and steelfiber-reinforced concrete. , 10,12-15 $^{\text {These studies }}$ show that an improvement in the matrix tensile characteristics improves slip, deformation, microcracking characteristics, and bond failure. Nevertheless, results show contradicting evidence on the effect of fibers on the bond strength and bond modulus. Rostasy and Hartwich ${ }^{13}$ tested specimens with 16-mm-diameter (ASTM \# 5) embedded bars and steel-fiber-volume fractions ranging between 0 and $2 \cdot 25 \%$. They concluded that the fiber presence increases neither the bond strength nor the bond modulus (i.e. the slope of the bond-slip curve). Ezeldin and Balaguru ${ }^{4}$ tested specimens with a maximum 25-mm (ASTM \# 8) bar size and steel-fiber-volume fractions of up to $0.75 \%$. They noted that the fiber presence does not significantly contribute to the bond strength of bars smaller than $16 \mathrm{~mm}$ (ASTM \# 5). Hamza and Naaman ${ }^{12}$ tested 25-mm (ASTM \# 8) deformed bars embedded in SIFCON matrix with $5 \%$ steel-fiber-volume fraction and concluded that fibers increase the bond strength and pull-out work. They also indicated that the discrepancy in the previously reported results is probably due to the low fiber-volume fractions and non-representative specimens used by different authors. 
Finally, except for the research conducted by Hamza and Naaman, ${ }^{12}$ no information exists on the effect of the increased tensile strength and toughness on the reinforcing-bar pull-out response. A significant increase in tensile strength and toughness is the main feature of new highperformance FRCs (HPFRCs) (e.g. SIFCON). These HPFRCs are capable of exhibiting pseudostrain-hardening behavior when loaded beyond the elastic limit, i.e. they behave like ductile metals when overloaded. This feature makes them very attractive for the design of advanced structural elements that have increased strength and ductility and improved over-all safety. One of the important issues for the design of such elements is knowledge of the pull-out response of reinforcing bars embedded in HPFRC matrices, which is the topic of the research reported here.

\section{Background on HPFRC exhibiting pseudo-strain-hardening}

HPFRCs made of short discontinuous randomly oriented fibers, exhibiting strain-hardening behavior, were used in this research. Generally, the use of fibers in cement composites leads to an increase in composite strength and ductility. The additional advantage of using an HPFRC exhibiting strain-hardening is that when it is loaded beyond the elastic limit, it exhibits a significant increase in the composite strain capacity, leading to an enormous increase in fracture toughness. For strain-hardening to occur, it is necessary that conditions for multiple cracking are met at the onset of cracking. ${ }^{16-18}$ This means that, once the first crack forms, the fiber reinforcement in the concrete composite must be capable of sustaining stress acting across the crack and transferring it back into the cement-composite matrix through the interfacial shear, thus leading to the formation of another crack..$^{16-18}$ In random discontinuousfiber composites, this happens when the bridging fibers have sufficient numbers, a sufficiently high bond strength and embedment length to take the bridging load. If this condition is not met at the onset of the first crack, fibers will be pulled out, which results in a pseudo-brittle type of failure characteristic of ordinary FRCs. ${ }^{18,19}$

\section{Terminology}

In order to classify the different types of stress-strain and load-slip behavior observed in this research, the following nomenclature is introduced. (i) Classes describing material tensile stress-strain behavior:

- brittle behavior: stress-strain behavior in which the ratio between strains at the ultimate tensile stress and strains at the limit of proportionality is close to unity; this is the behavior common for the tensile response of plain concrete;

- pseudo-brittle behavior: stress-strain behavior in which the ratio is close to two; this behavior is common for the tensile response of 'ordinary' FRC, such as FRC with a $1 \%$ fiber-volume fraction used in this research;

- strain-hardening (pseudo-ductile) behavior: stress-strain behavior in which the ratio is greater than three (ratios as high as ten have been achieved), and there is a noticeable increase in stresses between the limit of proportionality and the ultimate stress; this behavior characterizes the tensile response of the HPFRC used in this research.

(ii) Classes describing reinforcing bar pull-out load-slip behavior:

- brittle behavior: load-slip behavior in which the ratio between the slip at the ultimate tensile load (i.e. bond strength) and slip at the limit of proportionality is close to unity;

- pseudo-brittle behavior: load-slip behavior in which the ratio is between one and two;

- slip-hardening behavior: load-slip behavior in which the ratio is close to or greater than three and there is a noticeable increase in load (i.e. bond stress) between the limit of proportionality and the ultimate stress.

Critical ratio values were selected in conjunction with the experimental findings of this investigation.

\section{EXPERIMENTAL PROGRAM}

\section{Specimen geometry}

The pull-out specimen type used in this research is shown in Fig. 2. Two bar sizes were used: 10 $\mathrm{mm}$ (ASTM \#3) and $25 \mathrm{~mm}$ (ASTM \# 8) bar size. The same specimen type, which is a modified version of Danish Standard DS2082 pull-out test, was also used by Ezeldin and Balaguru ${ }^{4}$ and 

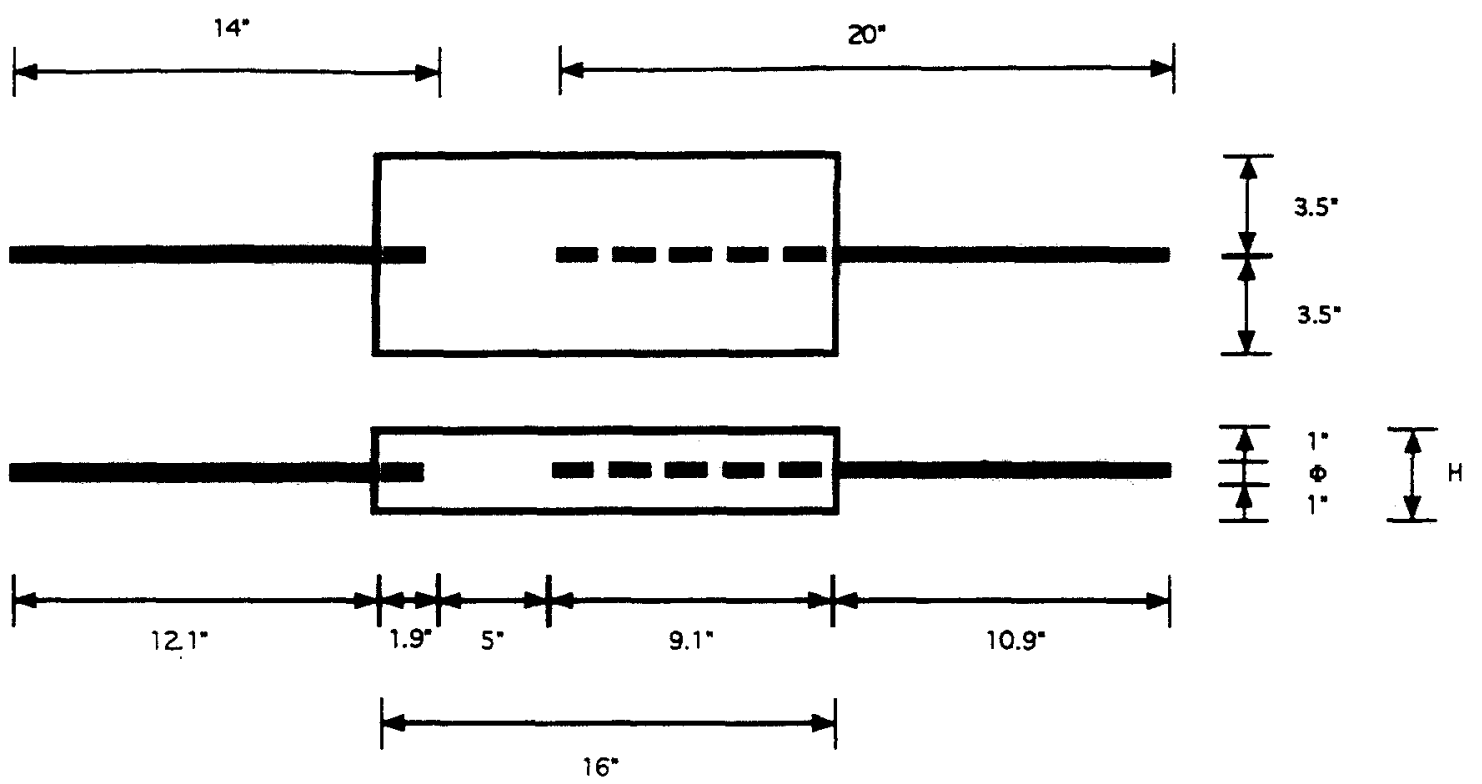

\begin{tabular}{|c|c|c|}
\hline $\begin{array}{l}\text { BAR } \\
\text { SIZE }\end{array}$ & $\Phi$ & $H$ \\
\hline ASTM $\# 3$ & $3 / 8^{\circ}$ & $2.375^{\circ}$ \\
\hline ASTM $\# 8$ & $1 "$ & $3^{\prime \prime}$ \\
\hline
\end{tabular}

Fig. 2. Layout of the pull-out specimen used in this study ( $1 \mathrm{in} .=25.4 \mathrm{~mm}$ ).

Chapman and Shah. ${ }^{5}$ The size of the specimen's cross-section was chosen to resist the tensile failure of the matrix. The shorter bar-embedded length was chosen so that the pull-out load was reached before the bar starts yielding. The longer bar-embedded length was chosen to prevent bond failure of that reinforcing bar.

Cover thickness directly affects the ultimate load level. Since the exact relationship between the cover thickness and the ultimate load level is not known at this time, a $25-\mathrm{mm}$ (1-in.) cover thickness was selected for all specimens. This is a common cover thickness used in structural elements. The effect of changes in cover thickness will be the subject of future study.

Compressive strength was determined by using 77-mm $\times 154-\mathrm{mm} \quad(3$-in. $\times 6$-in. $) \quad$ compressive cylinders. Uniaxial tensile response was determined by using $305-\mathrm{mm} \times 77-\mathrm{mm} \times 13-\mathrm{mm}$ (12in. $\times 3$-in. $\times 0.5$-in.) rectangular specimens.

\section{Materials, mix proportions, and casting procedure}

The goal of this research was to determine the effect of change in the material tensile strength and toughness on the pull-out response of deformed reinforcing bars. Four material systems, representing four different levels of strength and toughness, were therefore selected: (i) plain concrete, (ii) FRC with 1\% volume fraction of steel fibers, (iii) FRC with 3\% volume fraction of steel fibers, and (iv) HPFRC with $7 \%$ volume fraction of steel fibers. These four systems represent brittle, pseudo-brittle, and pseudo-ductile material behavior, as shown in Fig. 3 .

\section{Plain concrete}

The plain-concrete mix design was proportioned by using the standard $\mathrm{ACI}$ mix-design procedure for a 28-day compressive strength of $40 \mathrm{MPa}$ (approximately $6 \mathrm{ksi}$ ). Mix constituents included 9-mm (3/8-in.) coarse aggregate (CA) and fine aggregate (FA) (each meeting the grading requirements of ASTM C-33), Type I Portland Cement (C) (meeting ASTM C-150), and water (W). The SSD ratios of the mix components (by weight) for the plain-concrete mixes are $\mathrm{CA} / \mathrm{FA} / \mathrm{C} / \mathrm{W}=1.70 /$ $1 \cdot 70 / 1 \cdot 00 / 0 \cdot 45$.

\section{FRC and HPFRC}

The matrix used for the FRC and the HPFRC* mixes consisted of Type I Portland Cement $(\mathrm{C})$, a proprietary liquid micro-silica admixture (SF), a

${ }^{*}$ HPFRC matrix was designed at the University of Michigan by $\mathrm{Li}$ and $\mathrm{Wu} .^{20}$ 


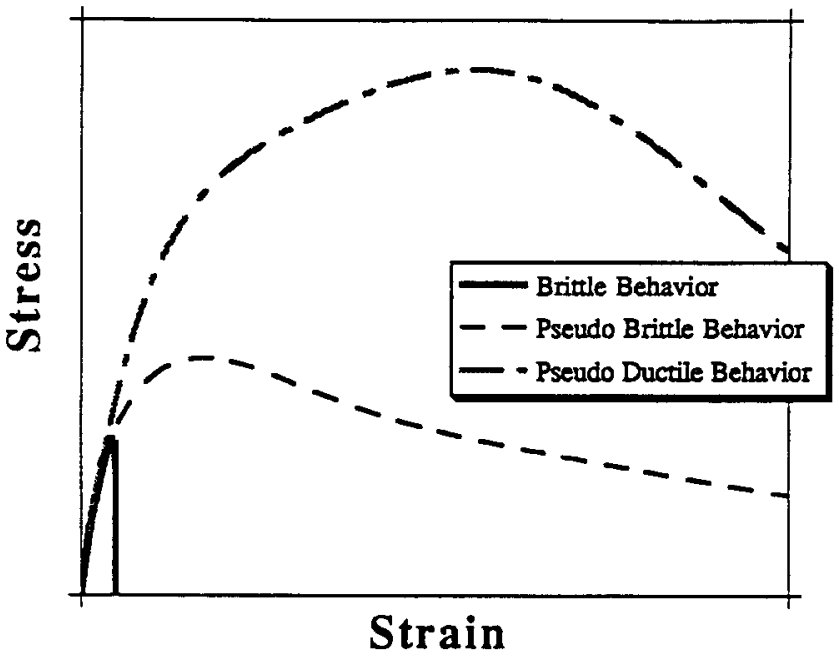

Fig. 3. Brittle, pseudo-brittle, and pseudo-ductile uniaxial tensile behavior characteristic of plain concrete, fiberreinforced concrete (FRC), and high-performance fiberreinforced concrete (HPFRC) exhibiting pseudo-strain-hardening, respectively.

melamine-based superplasticizer (SP) (meeting ASTM C-494), and water (W). The proportions (by weight) of the FRC-mix components are $\mathrm{C} / \mathrm{SF} / \mathrm{SP} / \mathrm{W}=1 \cdot 00 / 0 \cdot 20 / 0 \cdot 03 / 0 \cdot 27$. The HPFRC mix was further improved by the addition of an interface enhancing compound.$^{20}$ Straight, brasscoated steel fibers, $6 \mathrm{~mm}$ (approximately $1 / 4 \mathrm{in}$.) long and $0.15 \mathrm{~mm}(0.006 \mathrm{in}$.) in diameter (aspect ratio $=40$ ), were used in appropriate weight fractions to yield the necessary volume fractions. No coarse aggregate was used in FRC and HPFRC mixes.

\section{Mixing}

Plain-concrete specimens were mixed and cast in accordance with the relevant provisions of ASTM C-192. FRC materials were mixed in two stages. In the first stage, cement, silica fume, superplasticizer, and water were continuously mixed. Immediately after the completion of the first stage, fibers were gradually added, and the entire substance was continuously mixed during the second stage.

\section{Casting}

Two 76-mm $\times 152-\mathrm{mm}(3$-in. $\times 6$-in.) compression cylinders and one $305-\mathrm{mm} \times 76-\mathrm{mm} \times 13-$ $\mathrm{mm}(12$-in. $\times 3$-in. $\times 0.5$-in.) rectangular tensile specimen were cast with each pull-out specimen. All specimens were demolded after one day of moist curing and placed into water-curing tanks at room temperature for four weeks. Specimens were tested at an age of five weeks.

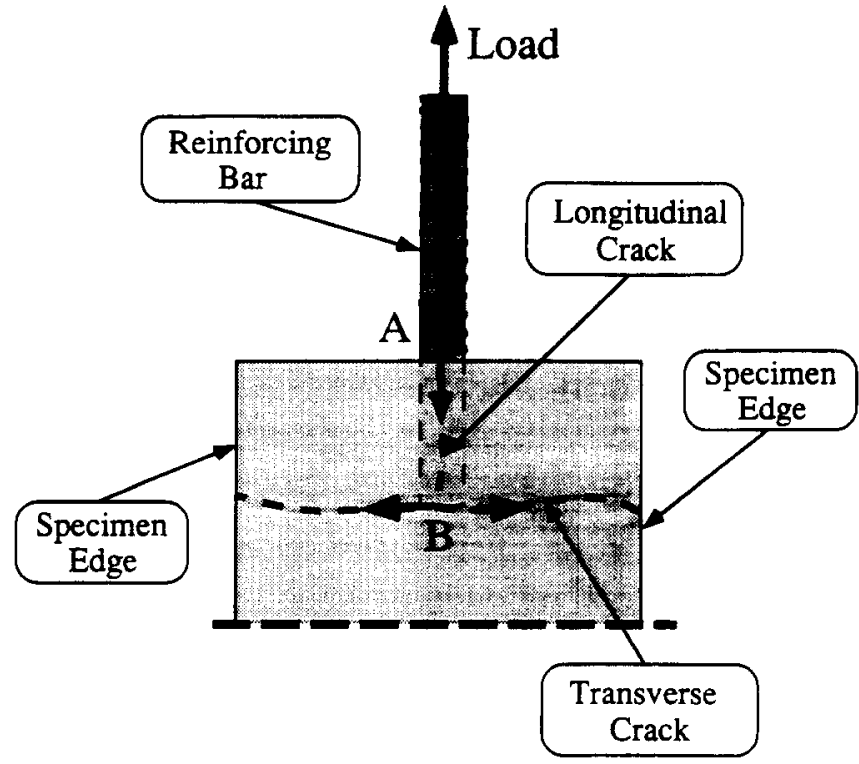

Fig. 4. Crack-pattern propagation.

\section{Test set-up}

Pull-out specimens were subjected to uniaxial tension by applying the tensile load through the free ends of the embedded bars. Tests were performed in a universal testing machine of $1330-\mathrm{kN}(300-\mathrm{k})$ capacity and with wedge grips. A loading rate of $3.3 \mathrm{kN} / \mathrm{min}(750 \mathrm{lbf} / \mathrm{min})$ was used. A small preload of $220 \mathrm{~N}(50 \mathrm{lbf})$ was applied to prevent slipping of the wedge grips. The pull-out slip displacement between the matrix and the reinforcement was measured by a linear-variable differential transducer (LVDT). The actual slip displacement was determined by adjusting the LVDT measurements to account for the elastic elongation of the bar segment between the specimen surface and the LVDT attachment point.

The companion cylinders were tested in compression in accordance with ASTM C-39. The companion rectangular tensile specimens were tested in pure tension.

\section{TEST RESULTS AND DISCUSSION}

\section{Crack development}

The following scenario of crack-pattern development was observed in all specimens.

(i) A longitudinal crack started propagating from point $A$, towards the embedded bar end (point B), as shown in Fig. 4.

(ii) Upon reaching point $B$, further opening of the existing crack is accompanied by the development of a transverse crack, which 
extends from point B toward the specimen edges. The specimen fails when the transverse crack reaches the specimen edges. Development of the transverse crack is a result of the matrix-tension failure through the net concrete section at the point of high stress concentration that develops at the bar end when the bar has already lost most of its bond.

In the case of a plain-concrete matrix, steps (i) and (ii) happened almost simultaneously. The presence of fibers leads to a slower and more stable crack development, resulting in a more ductile failure. Additionally, specimens made with FRC and HPFRC matrices exhibit a more tortuous crack path than the plain-concrete ones. No primary cracking ${ }^{2}$ has been observed in either plain-concrete or HPFRC pull-out specimens. This is contrary to the pull-out behavior reported by Goto $^{2}$ (see Introduction) and by Hamza and Naaman, ${ }^{2}$ who tested a \# 8-deformed reinforcing bar embedded in SIFCON beam specimens. In addition to multiple longitudinal cracks developing along the bar axis, Hamza and Naaman also observed fine hair-size cracks developing transversely to the reinforcing-bar axis (i.e. primary cracks in Goto's notation'). The discrepancy between results reported here and results reported by Goto and by Hamza and Naaman is attributed to:

(i) different specimen types, $\uparrow$ embedment-bar lengths, and cover thicknesses used in this work and used by other authors. ${ }^{2} .12$

(ii) crack 'visibility": all HPFRC composites used for the specimen matrices exhibit strain-hardening behavior; this behavior is attributed to the multiple-cracking phenomenon that occurs on a microscale when a sufficient number of fibers are present to bridge the initial crack and thus permit further loading and new cracking. ${ }^{16-18}$ For the HPFRC matrices used in this investigation, the multiple cracks are too narrow to be visible to the naked eye.

\section{Load-slip and bond-slip response}

Typical load-slip and average bond-slip curves obtained in this investigation are shown in Fig. 5.

†Hamza and Naaman used simple beam specimens, and thus their results incorporate effects of curvature in flexural-bond measurements.
The average bond stress was computed by assuming a uniform bond-stress distribution along the embedded portion of the bar. (Note that the actual bond-stress distribution is not uniform.) Curves of normalized load (i.e. the ratio between the load and maximum load) versus slip are shown in Fig. 6 . Results show that an increase in matrix tensile strength and toughness leads to a significant increase in bond strength, bond modulus, slip at maximum bond, and an over-all increase in ductility. This phenomenon is particularly pronounced when HPFRC exhibiting strain-hardening is used. The improvements in the bond performance cannot be attributed solely to the increased tensile strength of the matrix material. The other important factor is the increased toughness (i.e. strainhardening) of an HPFRC matrix, which prevents rapid failure along the initial crack and results in additional cracking elsewhere in the specimen. This leads to a significant increase in the pull-out deformation capacity and load redistribution and a general improvement in bond-resistance.

\section{Bond strength}

Bond strength increases with improvement in matrix tensile strength and toughness (i.e. with the increase in fiber-volume fraction), as shown in Fig. 5. The average maximum pull-out bond of a \# 3 bar embedded in 1\% fiber-volume-fraction FRC and HPFRC with $3 \%$ and $7 \%$ fiber-volume fraction was $1 \cdot 4,2 \cdot 6$, and 3.7 times the values for the same bar embedded in plain concrete, respectively. In the case of a \#8 bar embedded in $1 \%$ and 3\% fiber-volume-fraction FRC and HPFRC with $7 \%$ fiber-volume fraction, the average maximum bond increased $1 \cdot 6,3 \cdot 1$, and 4.9 times over the values for the same bar embedded in plain concrete, respectively.

\section{Slip}

The slip at maximum pull-out load increases with an improvement in matrix tensile strength and toughness, as shown in Fig. 6 . In the case of \#3 bars, the maximum slip was $1.5,1.8$, and 3.7 times as high for the $1 \%$ and $3 \%$ fiber-volume-fraction FRC and HPFRC with 7\% fiber-volume fraction, respectively, as for the same bar embedded in plain concrete. In the case of \#8 bars, the increase in slip at the peak load was even larger: $2 \cdot 6,3 \cdot 3$, and 6.5 times as high in the $1 \%$ and $3 \%$ fiber-volume-fraction FRC, and HPFRC with 7\% fiber-volume fraction, respectively, as for the same bar embedded in plain concrete. A similar 


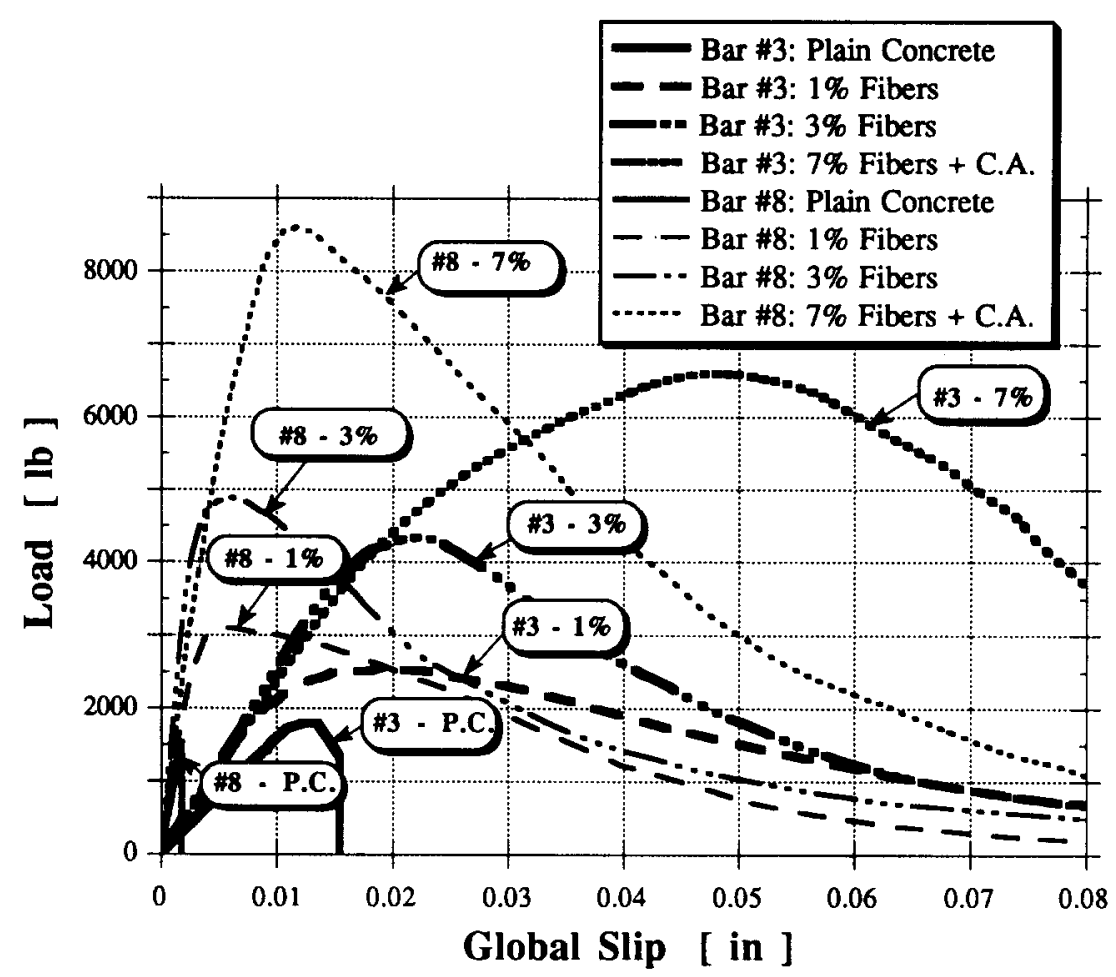

(a)

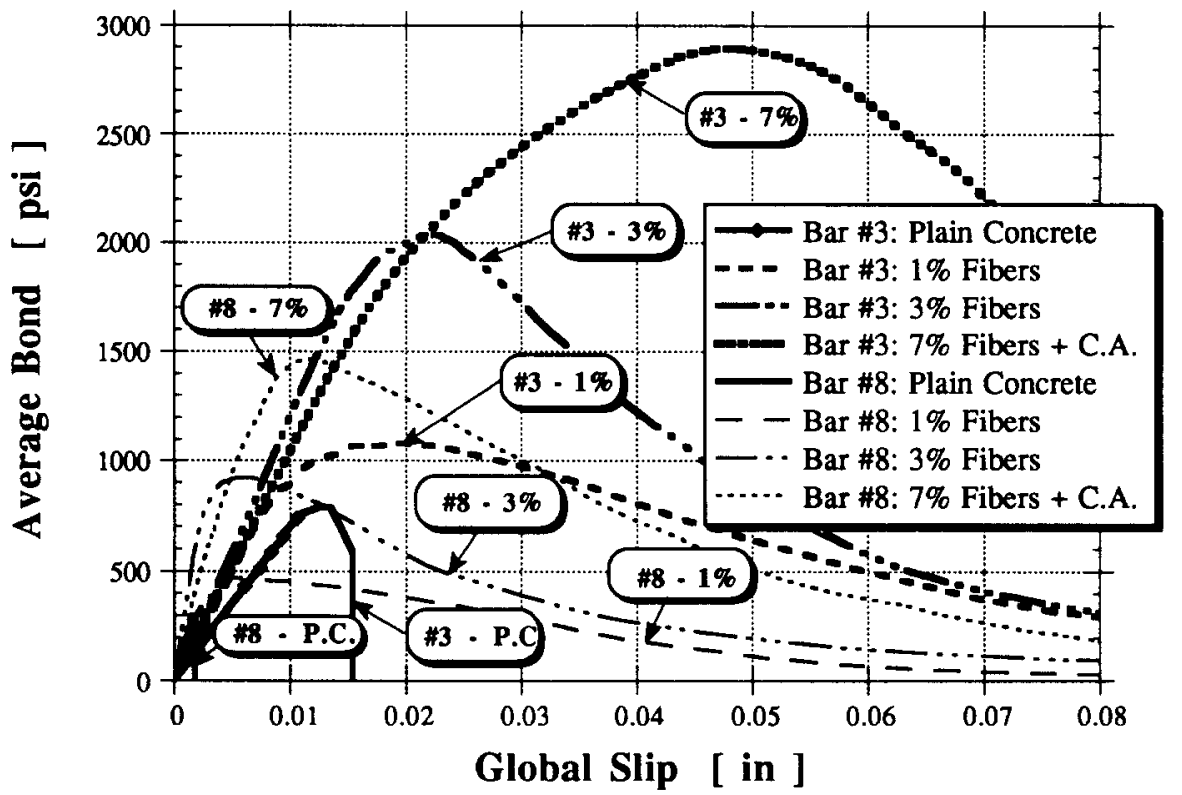

(b)

Fig. 5. Load-slip curves (a), and average bond-global-slip curves $(\mathrm{b})(1 \mathrm{lb}=4.45 \mathrm{~N} ; 1 \mathrm{psi}=0.0069 \mathrm{MPa} ; 1 \mathrm{in} .=25.4 \mathrm{~mm})$.

trend of increased slip at the maximum pull-out load with increased fiber content has been reported by Ezeldin and Balaguru ${ }^{4}$ and Hamza and Naaman. ${ }^{12}$ They concluded that the increase was due primarily to the development of a stable cracking pattern during the splitting failure of the matrix. A significant increase in the slip at the maximum pull-out load reported here is also related to the improved stability of the crack development, which in turn is related to the improved strain-hardening behavior of the matrix material.

\section{Ductility}

With the increase in the strain-hardening characteristics of the matrix material, both \#3 and \#8 bars exhibit increased bond strength, slip at peak load, and over-all ductility, as stated above. Nevertheless, a significant discrepancy exists in the type of pull-out behavior of \#3 and \#8 bars 


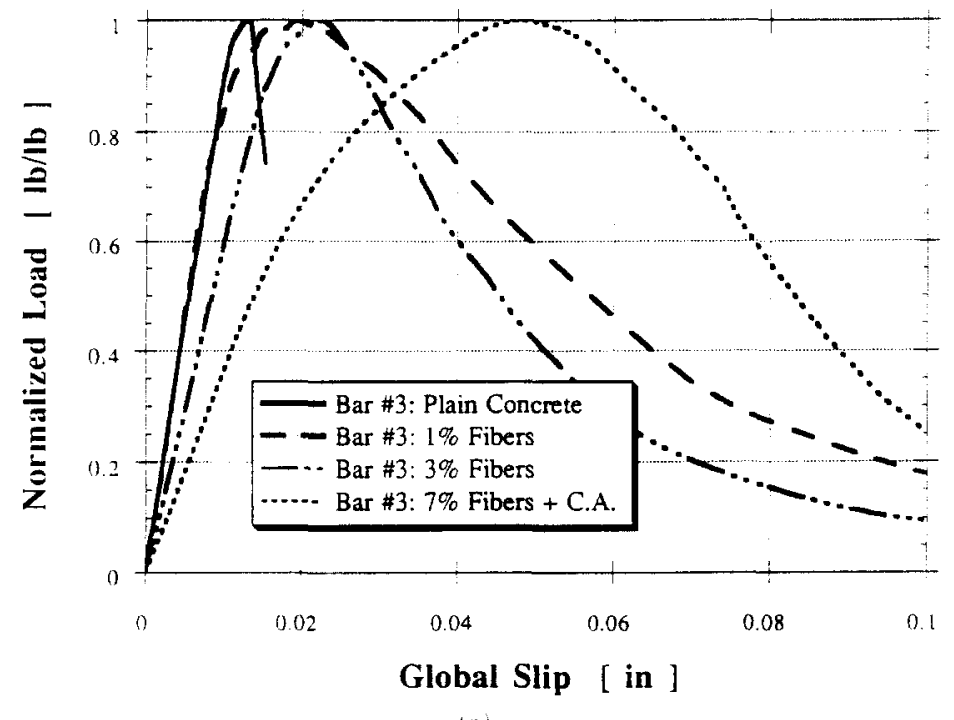

(a)

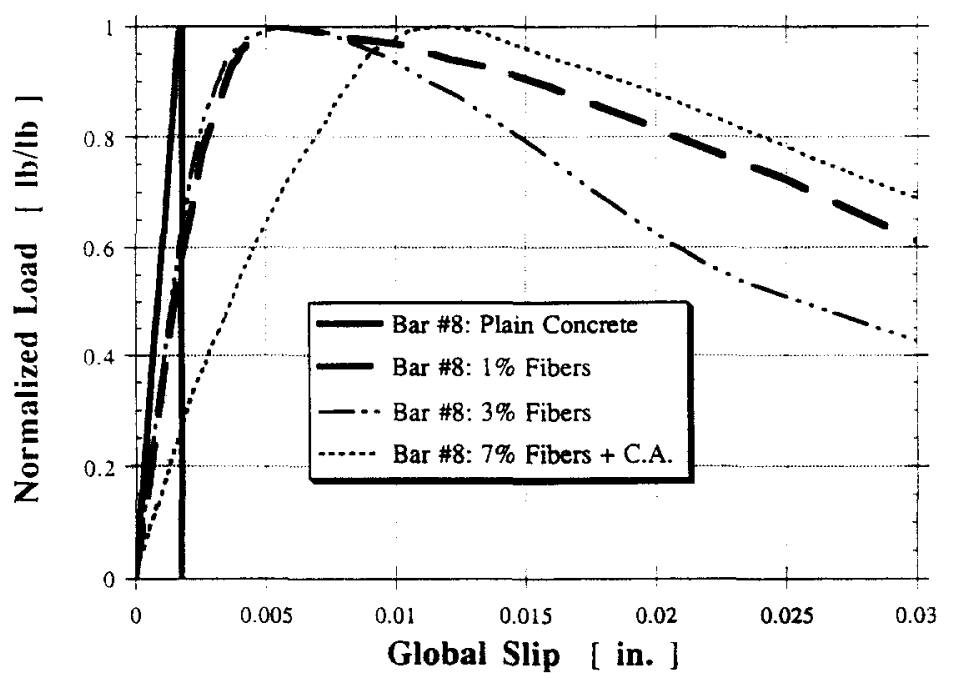

(h)

Fig. 6. Normalized load-slip curves for: (a) \# 3 bar specimens, and (b) \# 8 bar specimens $(1 \mathrm{in} .=25 \cdot 4 \mathrm{~mm})$.

embedded in the $7 \%$ fiber-volume-fraction HPFRC matrix: bar \# 3 exhibits distinctive sliphardening behavior, whereas bar \# 8 does not, as shown in Fig. 5. This discrepancy is attributed to the different levels of the lateral confinement, i.e. cover thickness, which can be expressed in terms of multiples of bar diameters. The cover thickness of bar \# 8 was one bar diameter, whereas the cover thickness of bar \# 3 was 2.7 times the bar diameter. Depending on the cover thickness, the failure mode can range from a brittle, tensile splitting (e.g. concrete with smaller cover thickness) to a more ductile, true pull-out failure characterized by crushing-shearing failure of the localized region around the bar (e.g. thick concrete covers).

- Plain concrete: In the case of plain-concrete specimens, bar \# 8 exhibited brittle splitting failure, whereas bar \#3 exhibited a small amount of ductility caused by internal crushing-shearing followed by final splitting failure.

- HPFRC: Strain-hardening of the HPFRC matrix, results in a disproportionally larger increase in bond strength relative to the increase in matrix tensile strength, as explained above. Nevertheless, the effect of strain-hardening on the bond ductility depends on the level of the lateral confinement and the resulting failure mode. Results obtained indicate that, if the failure mode is mainly splitting, as is the case with the $\# 8$ bar, strain-hardening will not result in a sliphardening behavior of the reinforcing bar. On the contrary, if the failure mode is primarily crushing-shearing pull-out, as is the case with the \# 3 bar, strain-hardening will 
result in a slip-hardening behavior of the reinforcing bar.

\section{Bond modulus}

In all cases, the addition of fibers increased the bond modulus as shown in Fig. 5(b). Nevertheless, the increase is not directly proportional to the increase in the fiber-volume fraction: specimens with $1 \%$ and $3 \%$ fiber-volume fraction exhibit higher bond modulus than specimens made with $7 \%$ fiber-volume fraction. Such behavior is attributed to the relationship between the fibervolume fraction and the level of matrix compaction (i.e. the quality of specimen casting) as explained below.

Najm $^{21}$ showed that, if very good material packing has been achieved (e.g. by using microsilica, finer sand particles, etc.), an increase in the fiber volume results in a large increase in the composite's elastic modulus. On the other hand, if 'regular' mixes were used (i.e. mixes in which no special attention was paid to the improved packing), an increase in the fiber-volume fraction results in increased porosity of the composite, which detrimentally affects the composite's elastic modulus. This effect is particularly pronounced in short-random-fiber composites. Hence, the actual elastic modulus will depend on the quality of the composite's compaction.

In the case of HPFRC mixes used in this research, a high fiber-volume fraction $\left(V_{\mathrm{f}}=7 \%\right.$ ) resulted in significantly lower workability. It is therefore concluded that, even though special high-frequency equipment was used during casting, the significantly lower workability of a $7 \%$ fiber-volume-fraction matrix resulted in a lower matrix compaction, leading to a lower elasticbond stiffness than is the case with $1 \%$ and $3 \%$ fiber-volume-fraction matrices. The same trend of a decrease in the elastic-bond modulus with an increase in the fiber-volume fraction was not observed with $1 \%$ and $3 \%$ fiber-volume-fraction matrices because an increase in fiber-volume fraction between $1 \%$ and $3 \%$ does not effect workability as detrimentally as is the case when the fiber-volume fraction is increased to high levels (e.g. $7 \%$ ). Hence the better workability, and thus compaction, of $1 \%$ and $3 \%$ fiber-volume-fraction matrices resulted in the higher bond stiffness than is the case with $7 \%$ fiber-volume-fraction matrices.

\section{Compressive- and tensile-strength tests}

Average compressive cylinder strengths, average tensile strengths, and relevant strain-energy density to failure, ${ }^{*}$ i.e. toughness values of the matrix material at the age of the pull-out tests are presented in Table 1. The compressive failures of the cylinders became progressively more ductile as the fiber-volume fraction was increased.

\section{Empirical equation of average bond stress}

The final goal of investigating the effect of HPFRC composites exhibiting pseudo-strainhardening on pull-out behavior is to develop a simple equation that can predict the pull-out strength. Such equations are commonly given in terms of the square root of the matrix compressive-cylinder strength (which is assumed to be related to the matrix tensile strength). For the purpose of comparison, the variation of bond strength with respect to compressive strength is shown in Fig. 7. The experimental results are compared with several existing models used for

*Strain energy desntiy to failure, i.e., toughness, was measured as the total area under the stress-strain curve up to material failure.

Table 1. Matrix characteristics and peak bond strength obtained in this research

\begin{tabular}{|c|c|c|c|c|c|}
\hline \multirow{2}{*}{$\begin{array}{l}\operatorname{Mix} \\
\left(V_{j}\right)\end{array}$} & \multirow{2}{*}{$\begin{array}{c}\text { Compressive } \\
\text { strength } \\
\left(f_{c}^{\prime}\right)\end{array}$} & \multirow{2}{*}{$\begin{array}{c}\text { Tensile } \\
\text { strength } \\
\left(f_{\mathrm{t}}^{\prime}\right)\end{array}$} & \multirow{2}{*}{$\begin{array}{c}\text { Tensile } \\
\text { toughness } \\
\left(T_{\nu}\right)\end{array}$} & \multicolumn{2}{|c|}{ Average peak bond strength } \\
\hline & & & & Bar \# 3 & Bar \# 8 \\
\hline $\begin{array}{l}\text { Plain } \\
\text { concrete } \\
(0 \%)\end{array}$ & $\begin{array}{l}38 \mathrm{MPa} \\
(5 \cdot 5 \mathrm{ksi})\end{array}$ & $\begin{array}{c}1.9 \mathrm{MPa} \\
(275 \mathrm{psi})\end{array}$ & $\begin{array}{l}0.7 \mathrm{MPa} \\
(0.1 \mathrm{psi})\end{array}$ & $\begin{array}{c}6.5 \mathrm{MPa} \\
(950 \mathrm{psi})\end{array}$ & $\begin{array}{l}2 \cdot 7 \mathrm{MPa} \\
(400 \mathrm{psi})\end{array}$ \\
\hline $\operatorname{FRC}(1 \%)$ & $\begin{array}{c}63.7 \mathrm{MPa} \\
(9 \cdot 2 \mathrm{ksi})\end{array}$ & $\begin{array}{c}3 \cdot 1 \mathrm{MPa} \\
(450 \mathrm{psi})\end{array}$ & $\begin{array}{l}9.7 \mathrm{MPa} \\
(1.4 \mathrm{psi})\end{array}$ & $\begin{array}{r}7 \cdot 2 \mathrm{MPa} \\
(1050 \mathrm{psi})\end{array}$ & $\begin{array}{l}3.4 \mathrm{MPa} \\
(500 \mathrm{psi})\end{array}$ \\
\hline $\operatorname{FRC}(3 \%)$ & $\begin{array}{l}71.8 \mathrm{MPa} \\
(10.4 \mathrm{ksi})\end{array}$ & $\begin{array}{l}4.5 \mathrm{MPa} \\
(645 \mathrm{psi})\end{array}$ & $\begin{array}{l}18.6 \mathrm{MPa} \\
(2.7 \mathrm{psi})\end{array}$ & $\begin{array}{l}14.5 \mathrm{MPa} \\
(2100 \mathrm{psi})\end{array}$ & $\begin{array}{l}6.5 \mathrm{MPa} \\
(950 \mathrm{psi})\end{array}$ \\
\hline $\begin{array}{c}\text { HPFRC } \\
(7 \%)\end{array}$ & $\begin{array}{l}88.3 \mathrm{MPa} \\
(12.8 \mathrm{ksi})\end{array}$ & $\begin{array}{c}6.0 \mathrm{MPa} \\
(870 \mathrm{psi})\end{array}$ & $\begin{array}{c}29 \cdot 0 \mathrm{MPa} \\
(4 \cdot 2 \mathrm{psi})\end{array}$ & $\begin{array}{l}18.6 \mathrm{MPa} \\
(2700 \mathrm{psi})\end{array}$ & $\begin{array}{c}9.6 \mathrm{MPa} \\
(1400 \mathrm{psi})\end{array}$ \\
\hline
\end{tabular}


predicting the ultimate average bond strength of bars embedded in a plain-concrete matrix.

(i) The ACI Code 22 suggested the following equation:t

$$
u_{\mathrm{ULT}}=\frac{9 \cdot 5}{d_{\mathrm{b}}} \sqrt{f_{\mathrm{c}}^{\prime}} \leq 800 \mathrm{psi}
$$

where $u$ is the 28 -day bond strength (psi), $f_{c}^{\prime}$ is the 28-day compressive-cylinder strength (psi), and $d_{\mathrm{b}}$ is the nominal bar diameter (in.).

(ii) Orangun et al. ${ }^{23}$ developed an equation that takes into account the effect of the matrix cover and embedment length. The equation was developed by using regression analysis and is given by:

$$
u_{\mathrm{ULT}}=\left(1 \cdot 22+3 \cdot 23 \frac{c}{d_{\mathrm{b}}}+53 \frac{d_{\mathrm{b}}}{l_{\mathrm{b}}}\right) \sqrt{f_{\mathrm{c}}^{\prime}}
$$

where $c$ is the matrix cover thickness (in.), and the rest of the notation is the same as for the ACI Code equation.

(iii) The equation suggested by Kemp ${ }^{6}$ was developed by using regression analysis and is given by:

$$
\begin{aligned}
u_{\mathrm{ULT}}= & 232 \cdot 2+2 \cdot 716 \frac{c}{d_{\mathrm{b}}} \sqrt{f_{\mathrm{c}}^{\prime}} \\
& +0 \cdot 201 \frac{A_{\text {trans }} f_{\text {trans }}^{\mathrm{y}}}{c_{\text {trans }} c}+195 \cdot 0 I_{\text {aux }} \\
& +21 \cdot 16\left(F_{\mathrm{d}} N\right)^{(1 . \cdot 66}
\end{aligned}
$$

where $A_{\text {trans }}$ is the area of transverse reinforcement (e.g. stirrups) in in. ${ }^{2}, f_{\text {trans }}^{y}$ is the yield strength of transverse reinforcement in psi, $c_{\text {trans }}$ is the center-to-center distance between adjacent transverse-reinforcement bars in inches, $I_{\text {aux }}$ is a parameter for auxiliary reinforcement (zero for a specimen without auxiliary reinforcement), $F_{\mathrm{d}}$ is the dowel force per reinforcing bar associated with shear cracking of a given section in kip/bar, and $N$ is the

†It should be noted that the newer ACI 318-89 previous for a bond were recently introduced into the Code. These provisions take into consideration the effect of lateral confinement on the bond performance. Nevertheless, the new Code does not predict the ultimate average bond strength, but instead gives only the necessary embedment length. The older ACI 318-83 Code that does predict the ultimate average bond strength was therefore used here for the purpose of comparison. number of reinforcing bars in the section. The rest of the notation is the same as previously stated. In the case of the specimen used in this research, only the first two terms are non-zero in eqn (3).

(iv) Darwin et al. conducted an extensive study on the bond strength and development length of reinforcing bars that are not confined by the transverse reinforcement. ${ }^{24}$ Expanding previous relationship developed by Orangun $e t$ $a l .{ }^{2.3}$ they developed the following expression for predicting the maximum bond force $A_{\mathrm{b}} f_{\mathrm{s}}\left(A_{\mathrm{b}}=\right.$ bar area, $f_{\mathrm{s}}=$ steel stress at bond failure):

$$
\begin{aligned}
\frac{A_{\mathrm{b}} f_{\mathrm{s}}}{\sqrt{f_{\mathrm{c}}^{\prime}}}= & 6.67 L_{\mathrm{d}}\left(C_{\min }+0.5 d_{\mathrm{b}}\right) \\
& \times\left(0.92+0.08 \frac{C_{\text {max }}}{C_{\text {min }}}\right)+300 A_{\mathrm{b}}
\end{aligned}
$$

where $A_{\mathrm{b}}$ is the area of (longitudinal) reinforcement (in. $\left.{ }^{2}\right), f_{s}$ is the stress in (longitudinal) reinforcement at bond failure, $L_{\mathrm{d}}$ is the barembedment length (in.), $c_{\mathrm{b}}$ is the matrix cover thickness (in.), $c_{\mathrm{s}}$ is half the distance between adjacent (longitudinal) bars (in.), $C_{\max }=\max \left(c_{\mathrm{b}}, c_{\mathrm{s}}\right)$, and $C_{\min }=\min \left(c_{\mathrm{b}}, c_{\mathrm{s}}\right)$. The rest of the notation is the same as previously stated. Equation (4) can be expressed in terms of $u_{\mathrm{ULT}}$ as:

$$
\begin{aligned}
u_{\mathrm{ULT}}= & \frac{\sqrt{f_{\mathrm{c}}^{\prime}}}{d_{\mathrm{b}} \pi L_{\mathrm{d}}}\left\{6.67 L_{\mathrm{d}}\left(C_{\min }+0.5 d_{\mathrm{b}}\right)\right. \\
& \left.\times\left(0.92+0.08 \frac{C_{\max }}{C_{\min }}\right)+300 A_{\mathrm{b}}\right\}
\end{aligned}
$$

Figure 7 shows a significant discrepancy between experimental results and listed empirical equations. This discrepancy is attributed to the fact that existing numerical models are not intended for use with fiber-reinforced composites exhibiting pseudo-strain-hardening features, as explained below.

The pull-out behavior of embedded reinforcing bars is characterized by the tensile failure of the surrounding matrix. ${ }^{2}$ This behavior was introduced in the existing models by using $\sqrt{f_{c}^{\prime}}$, which serves as a measure of the matrix tensile strength. The assumption that $\sqrt{f_{\mathrm{c}}^{\prime}}$ provides a measure of the concrete tensile properties has been used with success for many years over limited ranges of con- 


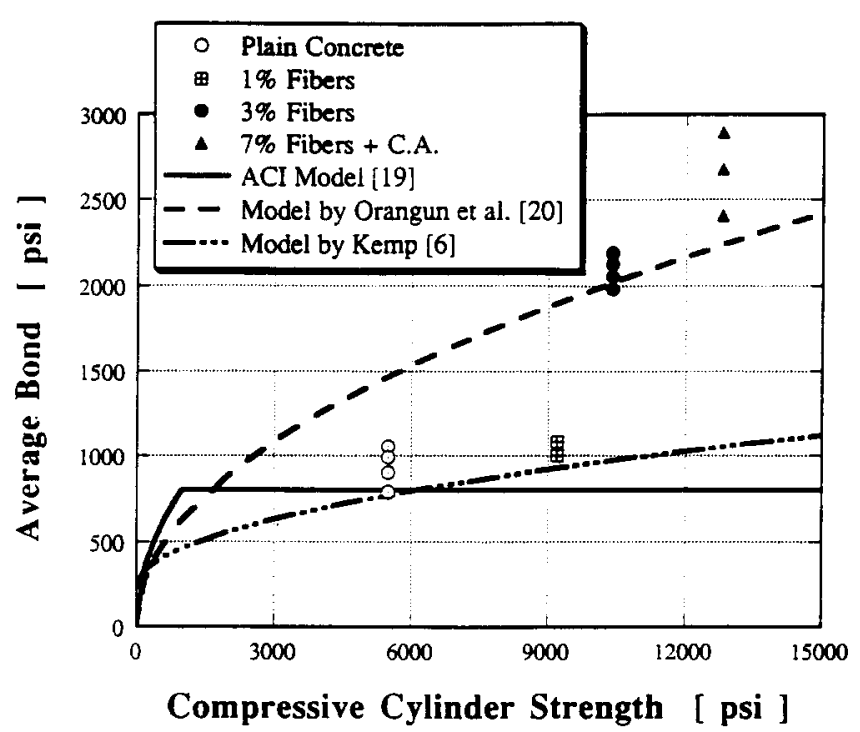

(a)

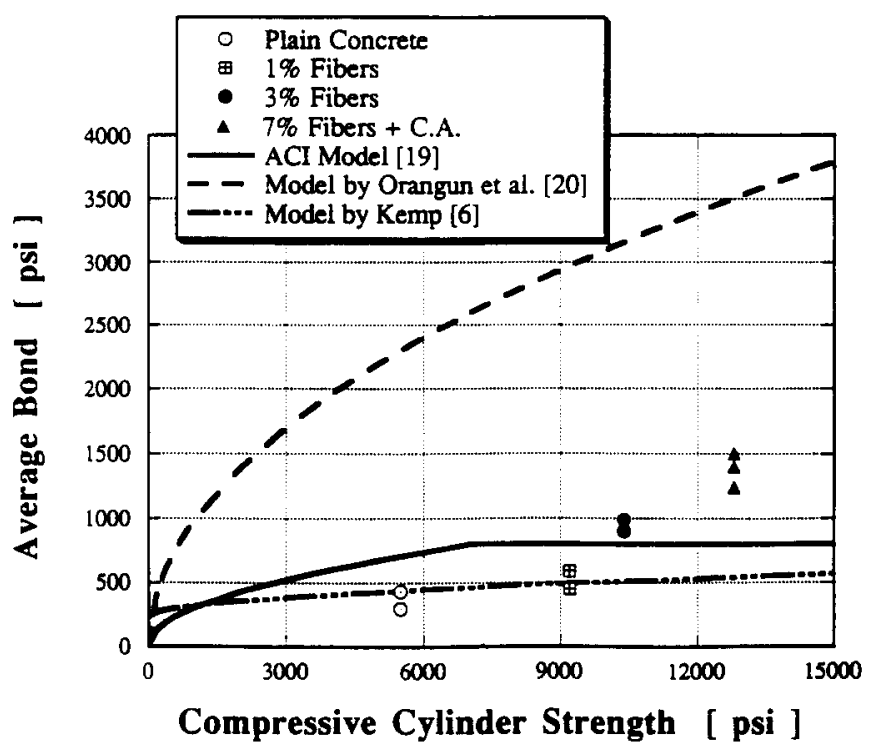

(b)

Fig. 7. Change of the average bond strength with respect to compressive-cylinder strength: (a) bar \#3, and (b) bar \#8 $(1 \mathrm{psi}=0.0069 \mathrm{MPa}$ )

crete strength. ${ }^{24}$ Results reported in this research show that this assumption cannot be used for predicting the bond strength of rebars embedded in fiber-reinforced-cement composites exhibiting pseudo-strain-hardening. Instead, an empirical model should be based on parameters describing the actual matrix tensile behavior, such as matrix tensile strength and toughness. To show the importance of the matrix tensile strength and toughness, the following simple model was developed by using regression analysis:

$$
u_{\mathrm{ULT}}=\left(0.5+0.89 \frac{c}{d_{\mathrm{b}}}\right) f_{\mathrm{t}}+\left(1 \cdot 2+0.83 \frac{c}{d_{\mathrm{b}}}\right) T_{\mathrm{t}}^{3}
$$

where $c$ is the cover thickness (in.), $d_{\mathrm{b}}$ is the bar diameter (in.), $f_{\mathrm{t}}$ is the matrix tensile strength (psi) and $T_{\mathrm{t}}$ is the matrix tensile toughness (psi). (Note that the bond strength is also likely to be a function of the embedment length, but on the basis of the current study, no parametric evaluation of these variables is possible.) Figure 8 shows very good agreement between the values predicted by eqn (6) and the experimental data over the entire range of matrix strengths and bar diameters investigated here. It should be noted that eqn (6) was developed by using a relatively small database that does not include the effect of different embedment lengths, which can significantly affect the average bond strength. Additional data are also needed to verify the relationship between the cover thickness (i.e. $c / d_{\mathrm{b}}$ ) and the bond strength. Hence, eqn (6) is only presented to indicate the importance of the matrix tensile strength and toughness and should not yet be used as an alternative 'design' equation. The development of an extensive database that will incorporate the effects of different embedment lengths and cover thicknesses, as well as the development of an alternative 'design' equation, is the goal of the future study.

\section{CONCLUSIONS}

The following conclusions can be drawn regarding the effect of increased matrix tensile strength and toughness on the reinforcing-bar bond and pull-out behavior.

(i) Pull-out load, slip at peak load, and pull-out work These parameters all increase with an increase in the matrix tensile strength and toughness. A significant increase is achieved by using HPFRC matrices exhibiting strain-hardening behavior. The maximum pull-out load of \# 3 and \# 8 bars is four and six times as large, respectively, for bars embedded in $7 \%$ fibervolume-fraction HPFRC as the ultimate load of the same bars embedded in plain concrete. Slip at peak load of \#3 and \#8 bars is four and seven times as large, respectively, for bars embedded in $7 \%$ fiber-volume-fraction HPFRC as the slip at peak load of the same bars embedded in plain concrete. Pull-out work of \# 3 and \# 8 bars embedded in $7 \%$ fibervolume-fraction HPFRC was increased to over 30 times the value of the same bars embedded in plain concrete (and over three times the 


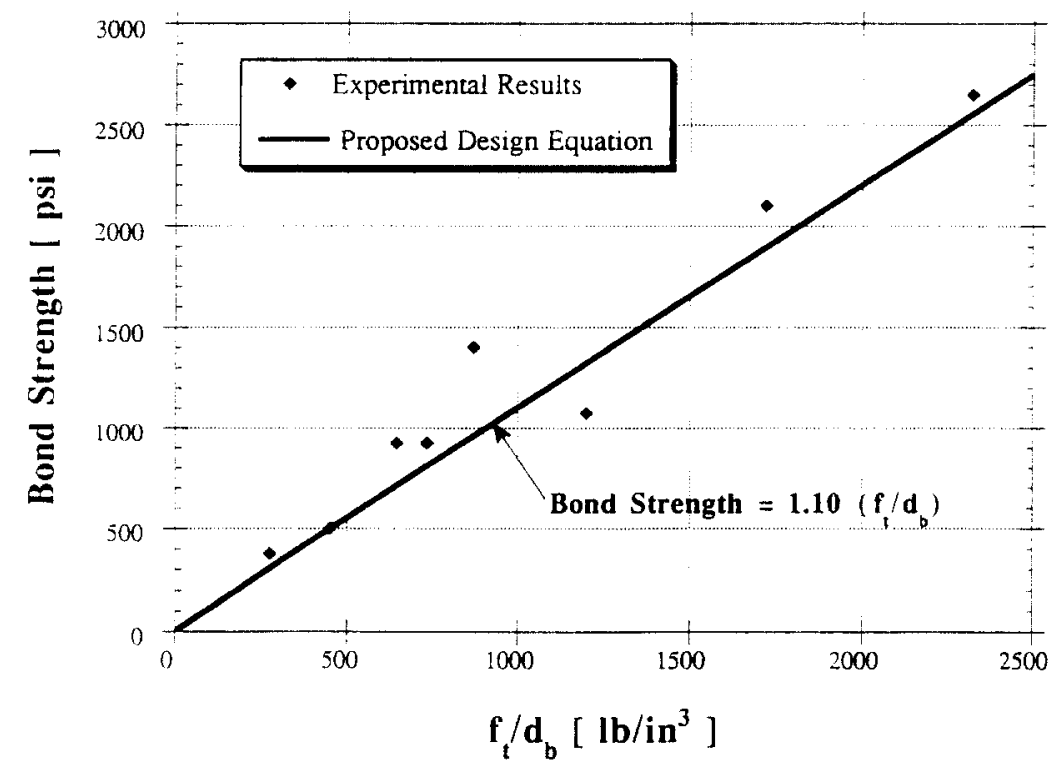

Fig. 8. Proposed equation for the bond strength ( $1 \mathrm{psi}=0 \cdot() 069 \mathrm{MPa} ; 1 \mathrm{lb}=4.45 \mathrm{~N} ; 1$ in. $=25 \cdot 4 \mathrm{~mm})$.

value of the same bars embedded in $1 \%$ FRC). Improved behavior is attributed to the strainhardening behavior of the matrix. This prevents rapid failure along the initial crack, and leads to additional cracking elsewhere in the specimen. The result is a significant increase in the pullout deformation capacity and load redistribution and a general improvement in bond-resistance.

(ii) Bond strength An increase in matrix tensile strength and toughness improves bond strength. The use of HPFRC matrices exhibiting strain-hardening results in a disproportionally larger increase in bond strength, relative to the increase in matrix tensile strength. Average maximum bond stresses exceeding $9.7 \mathrm{MPa}$ and $20.0 \mathrm{MPa}(1.4$ and $2.9 \mathrm{ksi}$ ) were observed in this study for deformed \# 8 and \# 3 bars embedded in $7 \%$ fiber-volume-fraction HPFRC, respectively. This represents approximately four and five times the values of the same bars embedded in plain concrete, respectively.

(iii) Bond modulus An increase in matrix tensile strength and toughness also improves the elastic-bond modulus. Nevertheless, the bond modulus seems to be very sensitive to the level of the matrix compaction: very high fibervolume fractions significantly lower workability, resulting in lower matrix compaction and thus lower elastic-bond modulus, as compared with bond modulus obtained by using matrices with lower fiber-volume fraction. hence, a high fiber-volume fraction can have a detrimental effect on the resulting bond modulus.

(iv) Cracking An increase in the matrix tensile strength and toughness increases the bond stress at first visible cracking and prevents rapid failure along the initial crack. The use of HPFRCs exhibiting strain-hardening also results in additional cracking elsewhere in the specimen. This leads to a significant increase in the pull-out deformation capacity and a very gradual crack development. This is an important advantage of the HPFRC matrix from a durability standpoint.

(v) Lateral confinement Provided that the failure mode is primarily crushing-shearing pull-out, as is the case with the \#3 bar, strainhardening will result in slip-hardening behavior of the reinforcing bar. The failure mode is related to the lateral confinement, such as cover thickness and/or the presence of stirrups.

(vi) Prediction of bond strength Existing empirical equations do not adequately take into consideration matrix tensile properties and thus cannot be used for predicting the bond behavior of reinforcing bars embedded in HPFRC matrices. A new equation that incorporates strain-hardening characteristics of the matrix needs to be developed. The empirical equation developed here shows that strainhardening characteristics can be introduced by including the matrix tensile strength and toughness rather than the matrix compressive strength. This equation should be further developed to incorporate other pull-out variables 
that were not available in this study, such as the effect of lateral confinement (i.e. the cover thickness and/or the presence of stirrups), the effect of embedment length, etc. Clearly, any equation used to predict the pull-out behavior of the new breed of high-performance cementitious composites must properly incorporate the matrix strain-hardening features.

\section{ACKNOWLEDGMENTS}

The authors would like to acknowledge the valuable comments and encouragement of Professors Antoine E. Naaman and Victor C. Li. Our gratitude also goes to Dr H. C. Wu, who has worked extensively on the matrix selection and design. Finally, the authors would like to thank Professor Victor C. Li for allowing the use of a new HPFRC matrix developed by $\mathrm{Li}$ and $\mathrm{Wu}$ at the University of Michigan, Ann Arbor.

\section{REFERENCES}

1. Park, R. \& Paulay, T., Reinforced Concrete Structures. John Wiley \& Sons, New York, NY, USA, 1975.

2. Goto, Y., Cracks formed in concrete around deformed tension bars. ACI Journal, Proceedings, 68 (1971) 244-51.

3. Bazant, Z. P. \& Sener, S., Size effect in pullout tests. $A C I$ Materials Journal, 85 (1988) 347-51.

4. Ezeldin, S. A. \& Balaguru, P. N., Bond behavior of normal and high-strength fiber reinforced concrete. $A C I$ Materials Journal, 86 (1989) 515-23.

5. Chapman, R. A. \& Shah, S. P., Early-age bond strength in reinforced concrete. ACl Materials Journal, 84 (1987) 501-10.

6. Kemp, E. L., Bond in reinforced concrete: behavior and design criteria. ACI Journal, Proceedings, 83 (1986) 50-7.

7. Brettmann, B. B., Darwin, D. \& Donahey, R. C., Bond reinforcement to superplasticized concrete. $A C I$ Journal, Proceedings, 83 (1986) 98-107.
8. Ueda, T., Lin, I. \& Hawkins, N. M., Beam bar anchorage in exterior column-beam connections. ACI Journal, Proceedings, 83 (1986) 412-22.

9. Yerex II, L., Wenzel, T. H. \& Davies, R., Bond strength of mild steel in polypropylene fiber reinforced concrete. ACI Journal, 82 (1985) 40-5.

10. Spencer, R. A., Panda, A. K. \& Mindess, S., Bond of deformed bars in plain and fiber reinforced concrete under reversed cyclic loading. International Joumal of Cement Composites, 4 (1988) 3-7.

11. ACI Committee 408, Bond stress - the state of the art. ACl Journal, Proceedings, 63 (1966) 1161-90.

12. Hamza, A. M. \& Naaman, A. E., Bond strength of reinforcing bars in SIFCON, In Proceedings of $A S C E$ Engineering Mechanics Specialty Conference, Columbus, OH, USA, 1991.

13. Rostasy, F. S. \& Hartwich, K., Bond of deformed reinforcing bar embedded in steel fiber reinforced concrete. International Journal of Cement Composites and Lightweight Concrete, 10 (1988) 151-8.

14. Wecharatana, M. \& Chimamphant, S., Bond strength of deformed bars and steel fiber in high strength concrete. Materials Research Society, 114 (1985) 245-53.

15. Swamy, R. N. \& Al-Noori, K., Bond strength of steel fiber reinforced concrete. Concrete Journal, 8 (8) (1974) 36-7.

16. Li, V. C. \& Leung, C. K., Steady state and multiple cracking of short random fiber composites. $A S C E$ Journal of Engineering Mechanics, (1992) 2246-64.

17. Tjiptbroto, P. \& Hansen, W., Tensile strain hardening and multiple cracking in high-performance cementbased composites containing discontinuous fibers. $\mathrm{ACl}$ Materials Journal, 90 (1993) 16-25.

18. Tjiptbroto, P. \& Hansen, W., Model for predicting the elastic strain of fiber reinforced composites containing high volume fractions of discontinuous fibers. $A C I$ Materials Journal, 90 (1993) 134-42.

19. Li, V. C. \& Wu, H. C., Conditions for pseudo-strain hardening in fiber reinforced brittle matrix composites. Applied Mechanics Review, (1992) 390-8.

20. Li, V. C. \& Wu, H. C., to be published.

21. Najm, H. S., Elastic modulus of high performance fiber reinforced cement based composites. Ph.D. thesis, The University of Michigan, USA, 1992.

22. ACI Committee 318 , Building code requirements for reinforced concrete (ACI 318-83). American Concrete Institute, Detroit, MI, USA, 1983.

23. Orangun, C. O., Jirsa, J. O. \& Breen, J. L., A re-evaluation of test data on development length and splices. $A C I$ Journal, Proceedings, 74 (1977) 114-22.

24. Darwin, D., McCabe, S. L., Idun, E. K. \& Schoenekase, S. P., Development length criteria: bars not confined by transverse reinforcement. ACI Structural Journal, (1992) 709-20. 